Aletheia, vol. 12, n 23, e114, diciembre 2021-mayo 2022. ISSN 1853-3701

Universidad Nacional de La Plata

Facultad de Humanidades y Ciencias de la Educación

Maestría en Historia y Memoria

\title{
Moler, Emilce (2020). La larga noche de los lápices. Relatos de una sobreviviente. Buenos Aires: Marea editorial. 240 págs.
}

Matías F. Gronchi

gronchimatias@gmail.com

Facultad de Humanidades y Ciencias de la Educación.

Universidad Nacional de La Plata, Argentina

Cita sugerida: Gronchi, M. F. (2021). [Revisión del libro La larga noche de los lápices. Relatos de una sobreviviente por E. Moler]. Aletheia, 12(23), e114. https://doi.org/10.24215/18533701e114

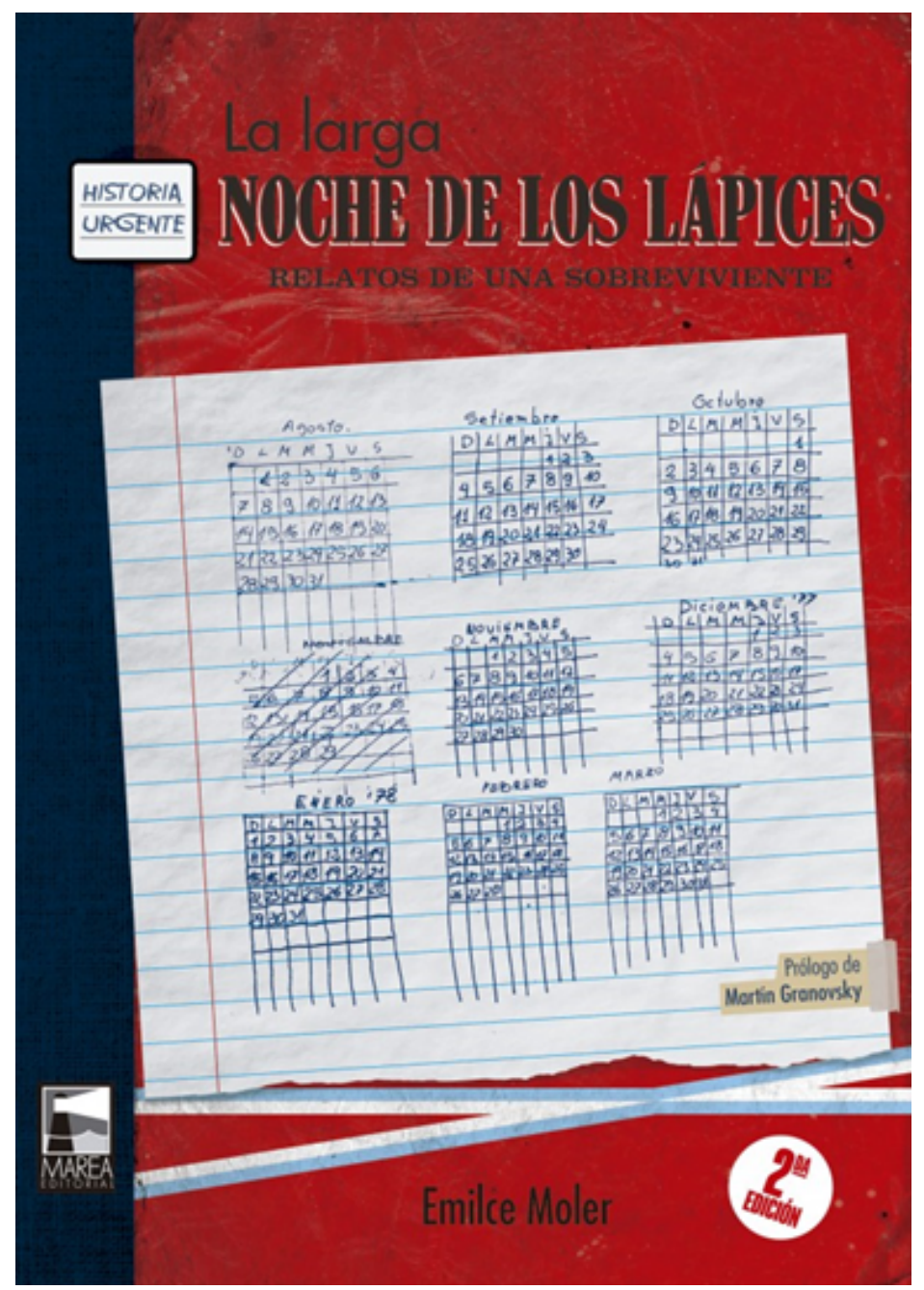


Aparecido en agosto de 2020, La larga noche de los lápices, relatos de una sobreviviente constituye el primer libro de Emilce Moler publicado por la editorial Marea. Repartido en 28 capítulos cortos el texto propone el relato autobiográfico de un pasado que ha sido narrado en numerosas oportunidades a través de testimonios, actos y entrevistas. La escritura como recurso aporta un nuevo soporte que, como señala la autora, se distancia del nerviosismo de los micrófonos y las multitudes para dar lugar a la pausa, a la reflexión y a los recuerdos que son compartidos con sus lectores y lectoras.

La presencia de múltiples temporalidades en cada capítulo propone un recorrido dinámico que entrelaza acontecimientos del pasado y el presente atravesados por objetos, olores y sonidos. La militancia temprana en la Unión de Estudiantes Secundarios; la detención- desaparición y el traslado al penal de Villa Devoto se articulan con la apertura democrática y la marca de un pasado que acompañará la búsqueda de verdad y justicia en contextos de impunidad o de reparación. El primer tiempo, el de la militancia juvenil en los 70, recupera la mirada de una joven que se encuentra en los márgenes de una decisión importante: asumir el compromiso de la militancia política. La autora describe las tensiones de una vida que se transforma ante la presencia de actividades políticas en fábricas y escuelas de La Plata. Profundizar, exiliar, aflojar son debates que Emilce narra como parte de un proceso complejo en el que la exposición del cuerpo involucra una red afectiva de familiares y compañerxs en un contexto de radicalización de la violencia.

En segundo lugar, el momento de la detención - desaparición y su "blanqueo" a disposición del Poder Ejecutivo Nacional con traslado al penal de Villa Devoto. En esta experiencia la autora repone la incertidumbre y el miedo del encierro aunque, también, reconstruye el encuentro con experiencias políticas de mujeres de distintas provincias del país. Devoto es para Emilce, el lento ritmo de una detenida que transcurre entre la espera, la pausa sin rebeliones ni acontecimientos destacables aunque con pequeñas resistencias a través de aprendizajes, vínculos y cartas amorosas que esquivan el control de la autoridad.

En tercer lugar, la libertad vigilada durante la dictadura, la apertura democrática y el testimonio en el juicio a las Juntas. En este apartado se destaca la compleja reinserción a la vida social que la autora atraviesa desde un exilio forzado en Mar del Plata. La vigilancia permanente y el seguimiento de las actividades operan como dispositivos de control que condicionan la integración en ámbitos educativos, laborales y en la formación de nuevos vínculos. La despolitización como mecanismo de reinserción se tensiona ante la apertura democrática y el desafío que señala Emilce de recuperar la iniciativa política y testimoniar, junto a su padre, en el juicio a las juntas militares.

Por último, de la resistencia a los indultos en la década del '90 emerge paulatinamente, en Emilce, la figura de sobreviviente. En este reconocimiento que interpela su identidad y que propone una nueva manera de percibir la experiencia, Emilce toma la palabra para disputar los sentidos de las narrativas consagradas, expresadas en el libo y la película "La noche de los lápices", y denunciar las políticas de impunidad. Durante el gobierno de Néstor Kirchner, con la derogación de las leyes de impunidad y la reapertura de los juicios, Emilce reconoce una nueva dimensión en su discurso enfocado en la construcción de puentes con las juventudes entre las luchas del pasado y los futuros deseados.

En paralelo, estas referencias temporales se articulan con materialidades, sonidos y espacios que Emilce utiliza como soporte para habitar el pasado. El cuaderno de tapas rojas que acompañó su estadía en Devoto, la elección de la vestimenta adecuada para una actividad política o el televisor de la infancia en la que Emilce y su familia miraban las novelas, presentan marcas materiales que invitan al lector o lectora a recorrer, no sólo la historia política, sino a reconstruir la estética juvenil, los consumos tecnológicos, las prácticas culturales de una época. En cuanto al espacio, el peso de un exilio forzado en Mar del Plata deja huella sobre la experiencia de la infancia y la juventud en la ciudad de La Plata. En esta distancia obligada se pueden observar los procesos de atribución de sentido que Emilce elabora sobre los micros en los que pega obleas de Montoneros o el frente de una escuela en la que reparten y arrojan volantes políticos. Esos lugares, producidos y apropiados por la autora, se integran en la narrativa como puntos de referencia constituidos por sus intervenciones. Por último, 
la melodía de una zamba, la intermitencia de una radio para aplacar el sonido de la tortura, por ejemplo, se cuelan en el texto como marcas sonoras que ocupan un lugar y que producen efectos sobre la autora que se replican en el tiempo.

Si La Noche de los Lápices, como sostiene Sandra Raggio (2017), es un modo de narrar determinados hechos, reunidos bajo un nombre que los singulariza en acontecimiento; esta autobiografía propone otros recorridos sobre ese pasado a partir de un relato que aborda el dolor sin banalizar el terror, el compromiso político de una generación, la vida cotidiana de los sentimientos y que reivindica la palabra como práctica para denunciar, reparar y transmitir. Como desea Emilce, este libro ofrece una caja de herramientas para el intercambio con las nuevas generaciones con la mirada puesta en el futuro.

\section{REFERENCIAS}

Raggio, Sandra (2017). Memorias de la Noche de Los Lápices. Tensiones, variaciones y conflictos en los modos de narrar el pasado reciente. La Plata: Universidad de La Plata; Posadas: Universidad Nacional de Misiones y Los Polvorines: Universidad Nacional de General Sarmiento. 216 pp. 